\title{
Low-Cost Digital System for Power Quality Monitoring
}

\author{
José Batista $^{1}$, Júlio S. Martins ${ }^{2}$ and João L. Afonso ${ }^{2}$ \\ ${ }^{1}$ Escola Superior de Tecnologia e de Gestão \\ Instituto Politécnico de Bragança \\ Campus de Sta. Apolónia, Apartado 134 - 5301-857 Bragança (Portugal) \\ phone:+351 273 303183, e-mail: jbatista@ipb.pt \\ ${ }^{2}$ Departamento de Electrónica Industrial \\ Universidade do Minho \\ Campus de Azurém - 4800-058 Guimarães (Portugal) \\ phone:+351 253 604701, fax:+351 253 510189, e-mail: jmartins@dei.uminho.pt, jla@dei.uminho.pt
}

\begin{abstract}
This paper describes the development of a low-cost digital system used for power quality monitoring and power management. The system uses voltage and current Hall sensors, a standard data acquisition board, and has its processing system based in LabVIEW ${ }^{\mathrm{TM}}$, running on a regular PC. The system acquires data continuously, and storage in files the events that result from the anomalies detected in the monitored power system. Several parameters related to power quality can be analysed through 6 different applications: "Scope and THD", "Strip Chart", "Wave Shape", "Sags and Swells", "Classical Values" and "p-q Theory Values". The acquired information can be visualized in tables and/or in charts. It is also possible to generate reports in HTML format. In this format, the reports can be sent directly to a printer, can be embedded in other software applications, or can be accessed through the Internet, using a web browser. It is also shown the potential of the developed system, namely the advantages of virtual instrumentation, regarding to flexibility, cost and performance in the scope of power quality monitoring and power management (after acquisition, processing and analysing of the information, data and warnings can be sent through Internet or wireless technology).
\end{abstract}

\section{Key words}

Power Quality Monitoring, Virtual Instrumentation, LabVIEW ${ }^{\mathrm{TM}}$, HTML automatic report generation, p-q Theory.

\section{Introduction}

Power quality is nowadays an important issue that involves electrical energy producers and consumers, and electrical equipment manufacturers. International standards concerning electrical power quality (IEEE-519, IEC 61000, EN 50160) impose that electrical equipments and facilities should not produce harmonic contents greater than specified values, and also specify distortion limits to the supply voltage. But power quality problems are not restricted to harmonics. Standard IEEE 1159 classifies various electromagnetic phenomena in power systems voltage (which are related to power quality problems): impulses, oscillations, sags, swells, interruptions, undervoltages, overvoltages, DC offset, harmonics, interharmonics, notches, noise, flicker, and frequency variation [1]. These problems are classified according to standard IEEE 1159-1995 in Table I.

Table I - Power quality problems classification.

\begin{tabular}{|c|c|c|c|c|}
\hline \multicolumn{3}{|c|}{ Category } & $\begin{array}{c}\text { Typical } \\
\text { Duration }\end{array}$ & $\begin{array}{c}\text { Typical } \\
\text { Amplitude }\end{array}$ \\
\hline \multirow{2}{*}{\multicolumn{2}{|c|}{ Transitory }} & Impulses & ns to $\mathrm{ms}$ & - \\
\hline & & Oscilation & $3 \mu \mathrm{s}$ to $5 \mathrm{~ms}$ & 0 to $8 \mathrm{pu}$ \\
\hline \multirow{8}{*}{$\begin{array}{l}\text { Short-time } \\
\text { Duration }\end{array}$} & \multirow{2}{*}{ Instantaneous } & Sag & 0.5 to 30 cycles & 0.1 to 0.9 \\
\hline & & Swell & 0.5 to 30 cycles & 1.1 to 1.8 \\
\hline & \multirow{3}{*}{ Momentaneous } & Interruption & 0.5 cycles to $3 \mathrm{~s}$ & $<0.1 \mathrm{pu}$ \\
\hline & & Sag & 30 cycles to $3 \mathrm{~s}$ & 0.1 to 0.9 \\
\hline & & Swell & 30 cycles to $3 \mathrm{~s}$ & 1.1 to 1.4 \\
\hline & \multirow{3}{*}{ Temporary } & Interruption & $3 \mathrm{~s}$ to $1 \mathrm{~min}$. & $<0,1 \mathrm{pu}$ \\
\hline & & Sag & $3 \mathrm{~s}$ to $1 \mathrm{~min}$. & 0.1 to 0.9 \\
\hline & & Swell & $3 \mathrm{~s}$ to $1 \mathrm{~min}$. & 1.1 to 1.4 \\
\hline \multirow{3}{*}{\multicolumn{2}{|c|}{$\begin{array}{l}\text { Long-time } \\
\text { Duration }\end{array}$}} & Interruption & $>1 \mathrm{~min}$ & - \\
\hline & & Undervoltage & $>1 \mathrm{~min}$. & 0.8 to 0.9 \\
\hline & & Overvoltage & $>1 \mathrm{~min}$ & 1.1 to 1.2 \\
\hline \multicolumn{3}{|c|}{ Voltage Unbalance } & steady-state & 0,5 to $2 \%$ \\
\hline \multirow{5}{*}{\multicolumn{2}{|c|}{ Waveform Distortion }} & DC Offset & steady-state & 0 to $0,1 \%$ \\
\hline & & Harmonics & steady-state & 0 to $20 \%$ \\
\hline & & Interharmics & steady-state & 0 to $2 \%$ \\
\hline & & Notching & steady-state & - \\
\hline & & Noise & steady-state & 0 to $1 \%$ \\
\hline \multicolumn{3}{|c|}{ Voltage Flutuations (flicker) } & steady-state & 0.1 to $7 \%$ \\
\hline \multicolumn{3}{|c|}{ Frequency Variations } & $<10 \mathrm{~s}$ & - \\
\hline
\end{tabular}

The economical importance of power quality can be quantified. According to EPRI (Electric Power Research Institute) power quality problems and electrical energy outages in the United States cost more than US\$ 119 billion per year [2]. All over the world there are many companies where these problems must be minimized or eliminated in order to increase productivity [3].

Power quality monitors are the best way to detect and diagnose problems in electrical power systems. However, these equipments are usually very expensive. The objectives of this paper are to present an advantageous and low-cost solution for power quality monitoring and power management, and to call attention for the necessity of improving power quality in modern power systems. 


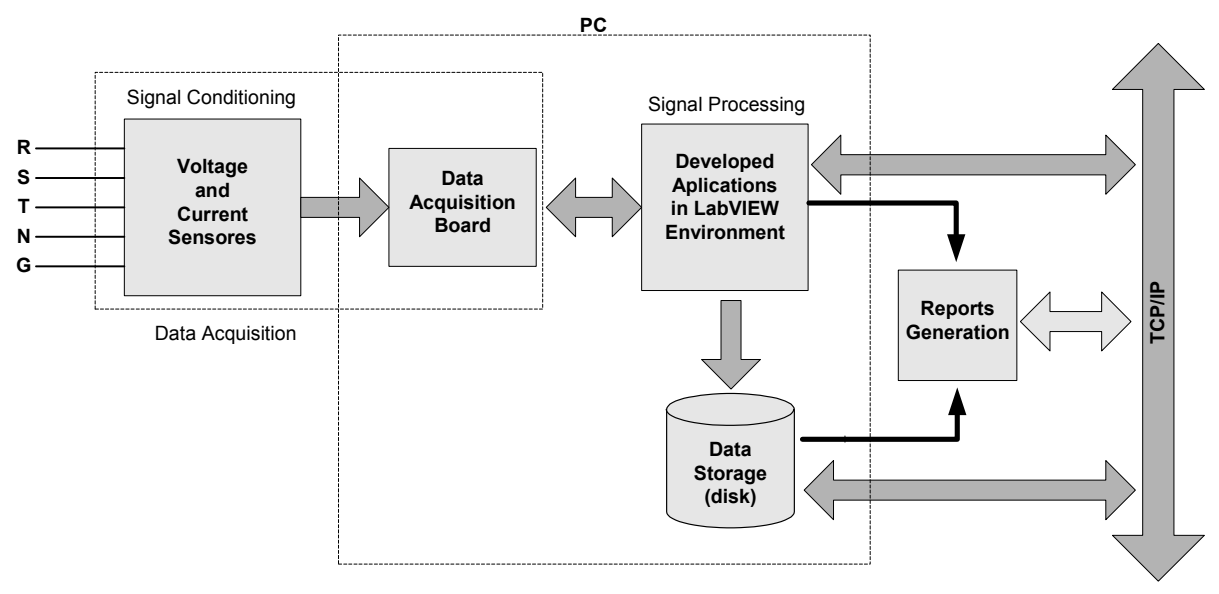

Fig. 1. Monitoring system block diagram

\section{Hardware Description}

The measurement system uses Hall-effect sensors 4 voltage sensors (LEM LV 25P) and 4 current sensors (LEM LTA 50P). The sensors outputs are small amplitude voltage signals. They can be used to measure the power system phase to neutral voltages $\left(v_{a n}, v_{b n}\right.$ and $\left.v_{c n}\right)$, neutral to ground voltage $\left(v_{n g}\right)$, phase currents $\left(i_{a}, i_{b}\right.$ and $i_{c}$ ), and neutral current $\left(i_{n}\right)$. These sensors convert the values of the measured voltage or current in small amplitude voltage signals. Furthermore, they isolate these signals from the power system potentials, allowing a safe operation of the developed monitoring system.

The digital data acquisition system uses a standard data acquisition board for the PCI bus (MIO-PCI-6024E, from National Instruments). Its main characteristics are: 16 analogic channels ( 8 channels in differential mode), 12 bits resolution, $200 \mathrm{ksamples} / \mathrm{s}$ sampling rate, $8 \mathrm{I} / \mathrm{O}$ digital lines, a 512 samples FIFO, 2 counters/timers with 24 bits resolution, and 2 digital trigger inputs, and several acquisition modes (including DMA - Direct Memory Access). This board works with two accessories: a connections box (SCH68) and a connection cable (SH68).

A standard desktop personal computer (PC), with a $450 \mathrm{MHz}$ Pentium II processor, running the Windows XP operating system, was used as the system processing unity.

\section{The Developed Monitoring System}

The monitoring system software was developed within the LabVIEW ${ }^{\mathrm{TM}}$ (from National Instruments) graphic programming environment. The system acquires data continuously, and stores in files the events that result from the detection of anomalies in the monitored power system (several parameters related to power quality are analysed). The acquired information can be visualized both in tables and/or through charts. It is also possible to generate reports in HTML (HyperText Markup Language) format. These reports can be sent directly to a printer, embedded in other Windows applications, or can be accessed through the Internet, using a web browser.
Furthermore, after the acquisition, processing and analyses of the information, data and warnings can be sent through Internet or wireless technology [4]. Figure 1 shows a block diagram of the developed system.

\section{Applications Developed in LabVIEW}

A program developed in LabVIEW is designated $V I$ (Virtual Instrument), because its appearance and functioning resemble real instruments, like scopes and multimeters. VI's use functions that manipulate the information coming from the user interface, and present it (after processing) or transfer it to files or to other computers.

After the definition of the general characteristics and specifications of the system, a top-down and modular methodology was followed for the development of the monitoring system software. Six applications were developed: "Scope and THD", "Strip-Chart", "Wave Shape", "Sags and Swells", "Classical Values", and "p-q Theory Values".

The developed applications consist of different software modules. Inside each module there is a first hierarchical level, which contains the main VI. Descending in the hierarchy, inside each sub-level, other operations can be accessed, which can be manipulated by the user through menus and submenus.

The developed system allows the measurement, monitoring and analyses of different parameters of the observed power system, by selecting the desired application. Next, the developed applications are described:

\section{A. Application "Scope and THD"}

This application is a typical example of virtual instrumentation, because it "imitates" a digital scope with 8 isolated channels ( 4 for voltages and 4 for currents) with the usual main basic functions: time base, vertical amplifier gain, trigger set-up (slope, level and source), and readouts (signals frequency, True RMS values, 


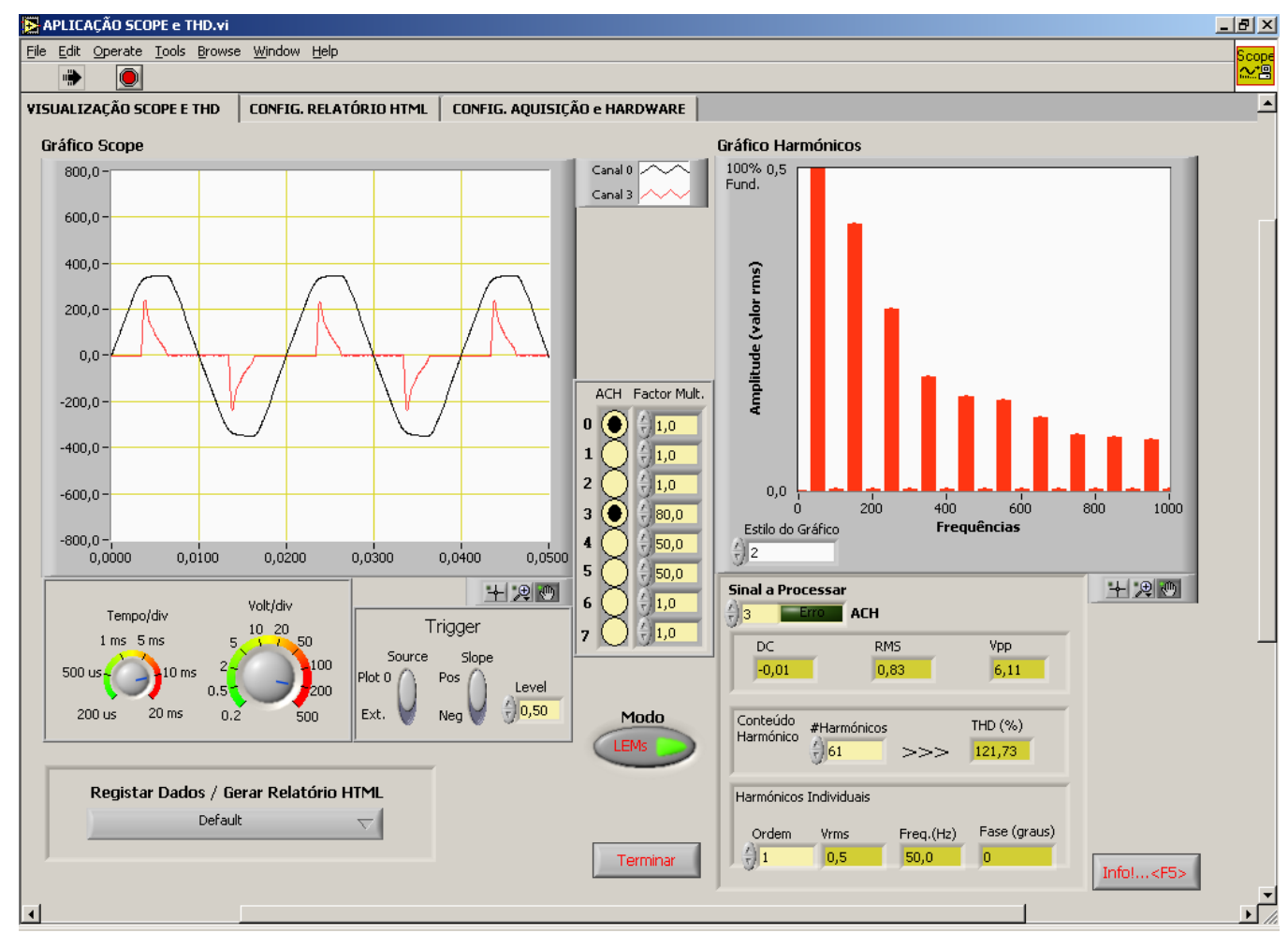

Fig. 2. Interface of the application "Scope and THD"

DC values, peak to peak values, etc). It is important to highlight that this application calculates the "True RMS" value, since many instruments in fact calculate a false RMS value, based on the calculation of the mean value of the "rectified" waveform (supposed to be sinusoidal), and on the crest factor value (the reason between RMS and mean values).

With this application it is possible to visualize up to 8 signals simultaneously, with a sampling rate of $25 \mathrm{kHz}$ per channel. It is also possible to calculate the harmonics and THD (Total Harmonic Distortion) of any desired signal.

The application can also generate reports in HTML format, and register data in files, which can be manipulated by other standard software tools that run on Windows, like Excel or Matlab. New functionalities can be easily added to this application, taking advantage of graphic programming and the use of the SubVI's potential.

Figure 2 shows the interface of the "Scope and THD" application as it appears on the PC screen.

\section{B. Application "Strip Chart"}

This application allows the calculation, registration and monitoring of RMS values along the time, usually for long time intervals. It can register the RMS values of 4 voltages ( 3 phase to neutral voltages and the neutral to ground voltage) and 5 currents ( 3 phase currents, the neutral current and the ground current). The ground current is not measured, as it can be calculated from the phase and neutral currents.

The user can set the strip chart time interval from 1 minute to 9 days. The signals can be visualised on-line, and the application can be interrupted at any time (in any case the data is always stored in the PC hard disk). It is possible to see the registered data at any time, and HTML reports can be produced. The program performs the RMS calculations each and every second, and the time interval of the registered data can be adjusted by the user, avoiding unnecessary data storage.

Figure 3 presents the interface for the "Strip Chart" application.

\section{Application "Wave Shape"}

This application detects distortions in the voltage waveforms of the 3 phases and registers these anomalies in file. In continuous acquisition, the samples values of the power system frequency cycle $n$ are compared with the samples values of cycle $n$ - 1 . If the result of the comparison exceeds a previously established limit (given by pre-specified tolerance values), the occurrence of an anomaly is considered, and the event is registered in file. There are always two cycles of the voltage signals being processed, and when a disturbance is detected, the samples of these two cycles, the samples of two cycles before them, and of two cycles after them, are all registered. Therefore, 6 cycles are registered when an anomaly is detected. The registering is made for the 3 phase voltages, even if the anomaly is detected in only one of the phases. 


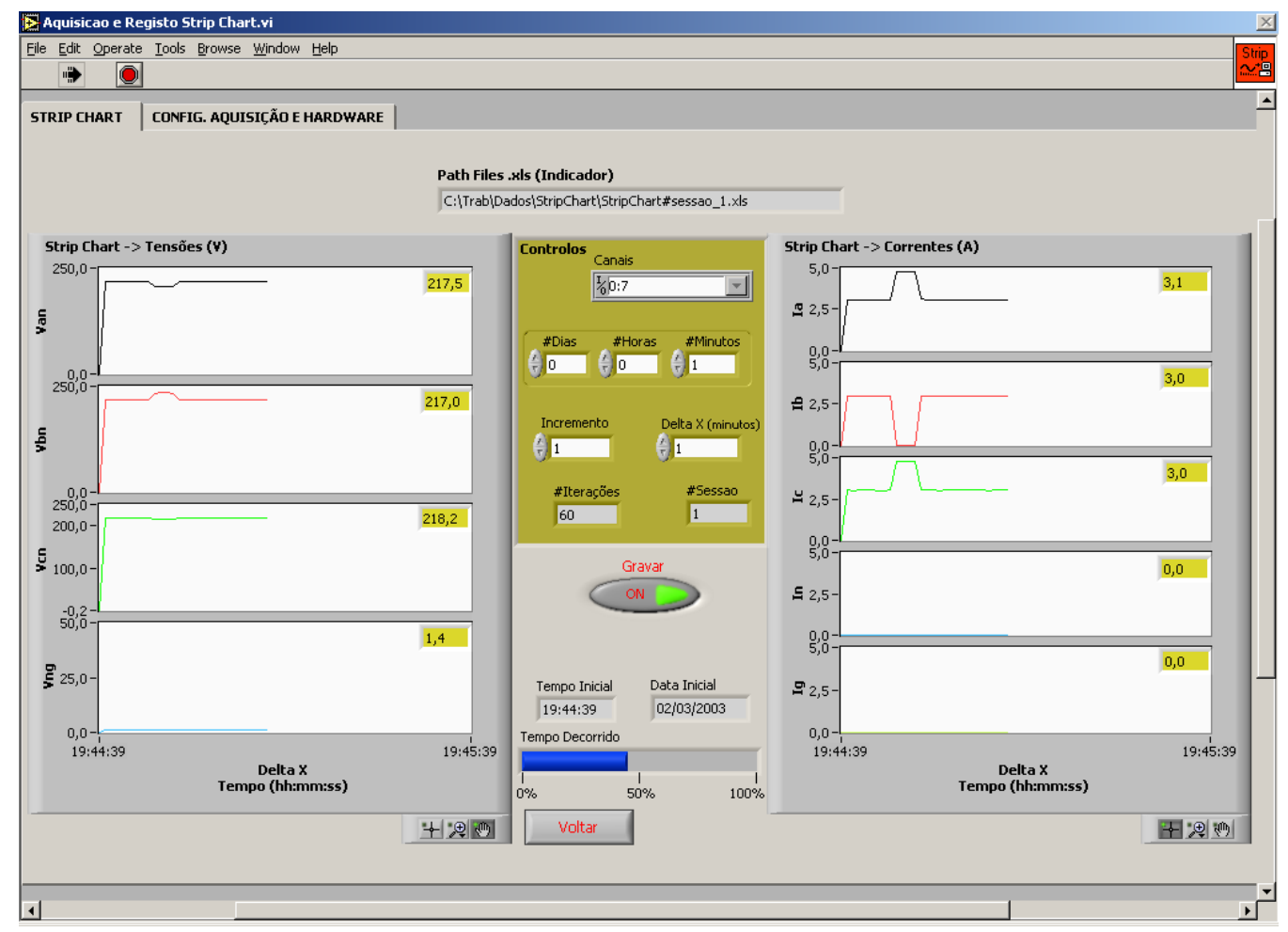

Fig. 3. Interface of the application "Strip Chart"

The critical aspect in the implementation and execution of this application relies on the fact that it must operate continuously without losing samples. The tests performed assured the correct operation of this application.

Figure 4 presents the interface of the "Wave shape" application that appears on the PC screen.

\section{Application "Sags and Swells"}

This application detects, and registers in file, short-time and long-time sag and swell events detected in the monitored voltages. The application simultaneously compares the measured values with the rated values of the phase to neutral voltages $\left(v_{a n}, v_{b n}, v_{c n}\right)$ and neutral to

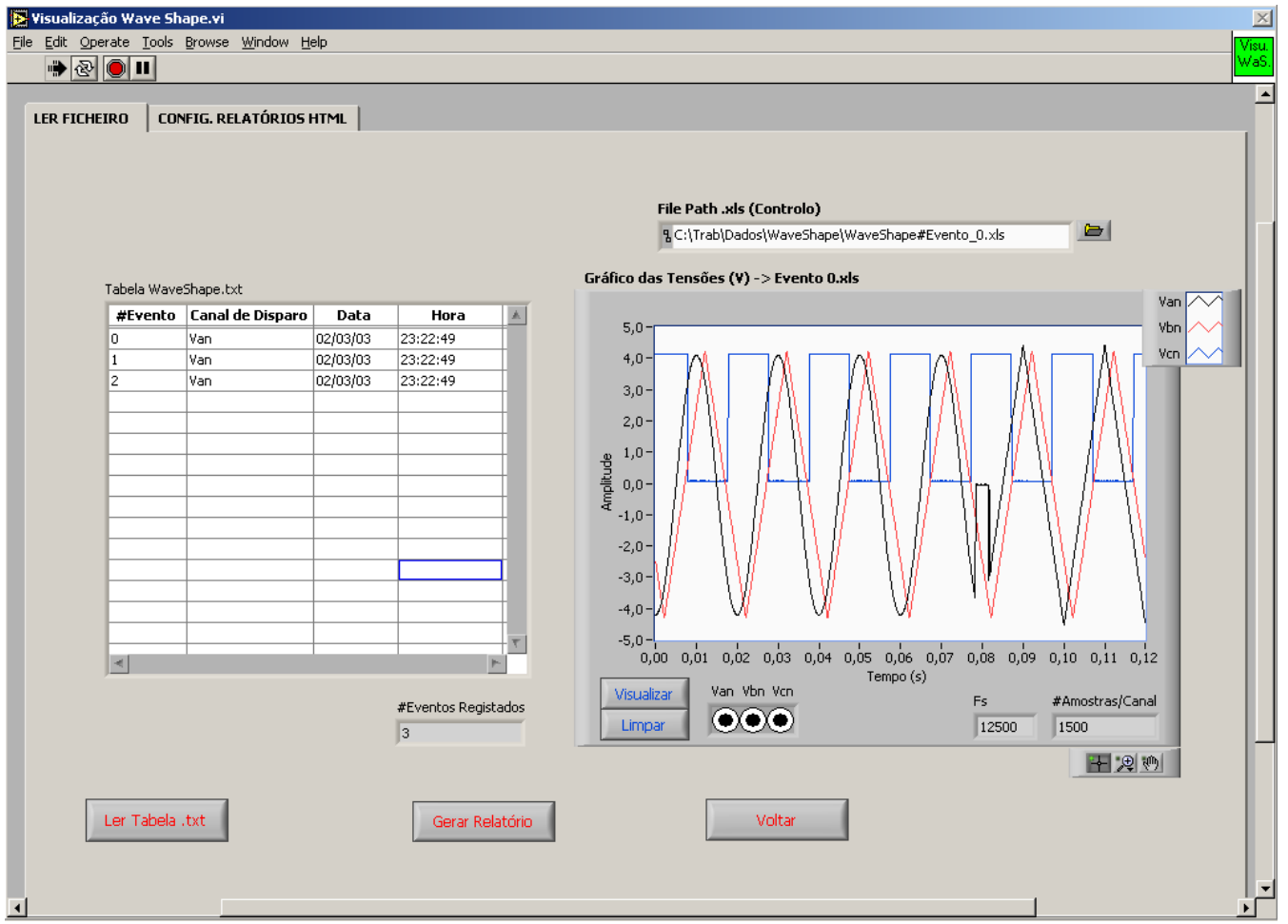

Fig. 4. Interface of the application "Wave Shape". 
ground voltage $\left(v_{n g}\right)$. The functioning tolerances are introduced by the user, which can apply different standards in relation to the accepted behaviour of the measured voltages. The user can also make an option for operation with analysis at each cycle or at each half cycle. Figure 5 shows a report (in Portuguese language) generated by the application "Sags and Swells".

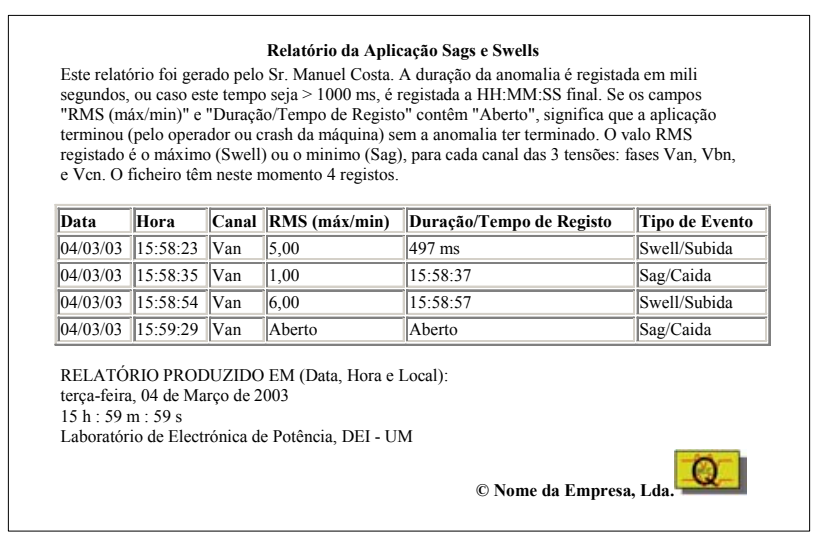

Fig. 5. Application "Sags and Swells": report example.

\section{E. Application "Classical Values"}

This application calculates the True RMS amplitude values and phase angles of each voltage and current, and also calculates the impedance amplitude and angle (per phase). In addition to the numerical values, the same information can be plotted, on-line (see Figure 6). These values can also be presented for different frequencies (this can be very useful when harmonics are present in the power system). Voltage and current unbalance, and total and displacement power factors are also calculated. The values of $\mathrm{kWh}$ (energy) and kVArh (reactive "energy") are also registered.

The application allows operation in two modes: "Acquisition" and "Simulation". In the "Simulation" mode all the calculations are made based on signals generated within LabVIEW. These signals parameters (amplitude, angle and frequency) are configured by the user, and it is possible to synthesize a signal with a fundamental frequency and its harmonics. In the "Acquisition" mode calculations are made with real signals, acquired by the voltage and current sensors.

\section{F. Application " $p-q$ Theory Values"}

This application calculates and shows numerically and graphically some of the values obtained by the $p-q$ theory. This theory, also known as "instantaneous power theory" was proposed in 1983 by Akagi et al. [5], [6] to control active filters. It is based on instantaneous voltage and current values in three-phase power systems with or without neutral wire, and is valid both for steady-state or transient operation, as well as for generic voltage and current waveforms. The $p$-q theory consists basically in an algebraic transformation (Clarke transformation) of the three-phase voltages and currents in $a-b-c$ coordinates into $\alpha-\beta-0$ coordinates, followed by the calculation of the $\mathrm{p}-\mathrm{q}$ theory instantaneous power components.

The knowledge of these components is extremely useful to analyse an observed power system, since they allows an easy understanding of several power quality problems (harmonics, reactive power, load unbalance, etc) in a three-phase power system [7].

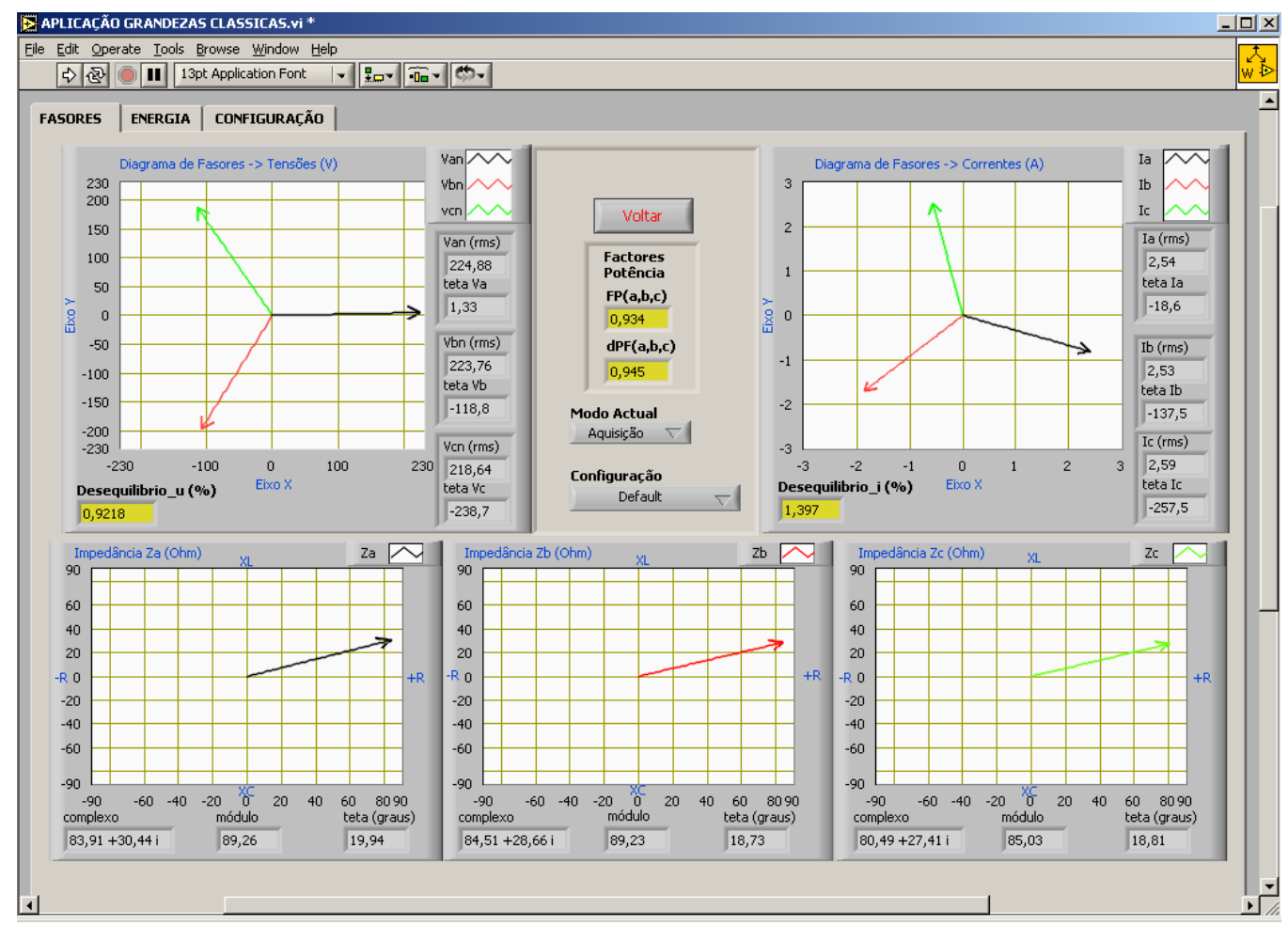

Fig. 6. Interface of the application "Classical Values". 
This application can also calculate the values of currents and instantaneous power that source would have to supply if a shunt active power filter was used to compensate for harmonics, reactive power and zero sequence current. The software computes all the quantities which are important to the control of the active filter, and allows the visualization of all relevant signals: voltages, currents and power components, at load, source and active filter. The signals can be shown in the $a-b-c$ or $\alpha-\beta-0$ coordinates and presented through and interface similar to the one of the Application "Scope and THD", showed in Figure 2.

The application allows three different modes of operation: "Acquisition", "Simulation LabVIEW" and "Simulation Matlab/Simulink". In the "Acquisition" mode all $p-q$ theory calculations are made from real voltage and current signals, obtained with the sensor values. The "Simulation LabVIEW" mode has all functionalities of the previous mode, but uses signals produced with LabVIEW VI's. Harmonic components can be added to any simulated voltages or currents. In the "Simulation Matlab/Simulink" mode the simulation and visualization of the signals is performed in the Matlab environment. It is done without closing the current application, which runs on LabVIEW. The Matlab simulation is executed through a $m d l$ file developed in Simulink. The menus for this graphical user interface were developed with the Matlab GUIDE (Graphical User Interface Development Environment) tool.

All 6 developed applications for the Low-Cost Digital System for Power Quality Monitoring provide data storage and report generation.

\section{Conclusion}

There are several types of equipments in the market that can be used to monitor power quality or to perform power management studies. However, they are usually very expensive.
This paper shows that it is possible to develop very useful equipment for power management and power quality monitoring, suitable for industrial or commercial facilities, or even for research purposes, using a reduced cost platform. To accomplish that, Hall-effect sensors, a generic data acquisition board, a regular $\mathrm{PC}$ and a graphical programming language (LabVIEW ${ }^{\mathrm{TM}}$ ), were used.

The use of the p-q theory in the analysis of three-phase power systems is also presented. This analysis was included in the developed equipment because it can be very useful to diagnose problems related to electrical power quality.

\section{References}

[1] Roger C. Dugan, Mark F. MacGranaghan, H. Wayne Beaty, Electrical Power Systems Quality, MacGraw-Hill, 1996.

[2] Gerg Mazurkiewicz, http://www.achrnews.com/CDA/ ArticleInformation/features/BNP_Features__tem/ 0,1338,62014,00.html, 2001.

[3] Ricardo Ross, Tatiana Assis, Luciano Brasil, "Investigação da Qualidade de Energia Eléctrica em Clientes Industrias da RGE”, IV SBQEE, Porto Alegre, Brasil, 2001.

[4] Jeffrey Travis, Internet Aplications in LabVIEW, Prentice Hall, 2000.

[5] H. Akagi, Y. Kanazawa, A. Nabae, "Generalized Theory of the Instantaneous Reactive Power in ThreePhase Circuits", IPEC'83 - Int. Power Electronics Conf., Tokyo, Japan, 1983, pp. 1375-1386.

[6] H. Akagi, Y. Kanazawa, A. Nabae, "Instanataneous Reactive Power Compensator Comprising Switching Devices without Energy Storage Compenents", IEEE Trans. Industry Applic., vol. 20, May/June 1984.

[7] J. Afonso, C. Couto and J. Martins, "Active Filters with Control Based on the p-q Theory", IEEE Industrial Electronics Society Newsletter, vol. 47, $n^{\circ} 3$, Sept. 2000, pp. 5-10. 